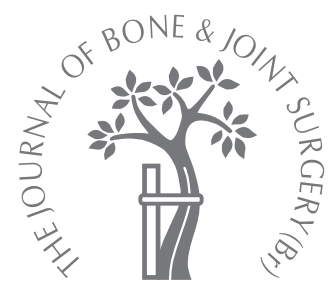

\title{
A prospective randomised controlled trial of autologous retransfusion in total knee replacement
}
A. Amin, A. Watson, J. Mangwani, D. H. Nawabi, R. Ahluwalia, M. Loeffler
From Colchester General Hospital, Colchester, England

\begin{abstract}
We undertook a prospective randomised controlled trial to investigate the efficacy of autologous retransfusion drains in reducing the need for allogenic blood requirement after unilateral total knee replacement. We also monitored the incidence of post-operative complications. There were 86 patients in the control group, receiving standard care with a vacuum drain, and 92 who received an autologous drain and were retransfused postoperatively. Following serial haemoglobin measurements at 24, 48 and 72 hours, we found no difference in the need for allogenic blood between the two groups (control group 15.1\%, retransfusion group $13 \%(p=0.439)$ ). The incidence of post-operative complications, such as wound infection, deep-vein thrombosis and chest infection, was also comparable between the groups. There were no adverse reactions associated with the retransfusion of autologous blood.

Based on this study, the cost-effectiveness and continued use of autologous drains in total knee replacement should be questioned.
\end{abstract}

\footnotetext{
A. Amin, MRCS(Eng), Specialist Registrar Trauma and Orthopaedics (Percival Pott Rotation)

J. Mangwani, MRCS,

Specialist Registrar Trauma and Orthopaedics

D. H. Nawabi, MA

MRCS(Eng), Specialist

Registrar Trauma and

Orthopaedics (Percival Pott

Rotation)

R. Ahluwalia, MRCS

Specialist Registrar Trauma and

Orthopaedics

- M. Loeffler, FRCS, Consultant

Orthopaedic Surgeon

Department of Trauma and

Orthopaedics

Colchester General Hospital,

Turner Road, Colchester $\mathrm{CO} 4$

5JL, UK.

A. Watson, FRCS(Tr \& Orth),

Consultant Orthopaedic

Surgeon

Department of Trauma \&

Orthopaedics

Prince Alexandra Hospital,

Hamstel Road, Harlow CM2O

10X, UK.

Correspondence should be sent to $\mathrm{Mr}$ A. Amin at 30 Church Drive, North Harrow, Middlesex HA2 7NR, UK; e-mail: amitamin@doctors.org.uk

(C)2008 British Editorial Society of Bone and Joint Surgery doi:10.1302/0301-620X.90B4. $20044 \$ 2.00$

$J$ Bone Joint Surg [Br]

2008;90-B:451-4.

Received 3 August 2007;

Accepted after revision 18

December 2007

Although it has been reported that 'there is no conclusive evidence for or against the use of drains in joint arthroplasty', ${ }^{1}$ there remains controversy regarding the best method of blood conservation. The risks associated with allogenic blood transfusion are well documented $^{2-4}$ and numerous strategies have been employed to conserve blood following total joint arthroplasty.

Autologous retransfusion drains have become increasingly popular and their use has been supported by a number of studies..$^{5-13}$ Alternative autologous strategies, including preoperative donation ${ }^{14}$ and intra-operative cell salvage (processed blood), ${ }^{15}$ have distinct disadvantages, making their routine application undesirable. Techniques directed towards reducing blood loss, such as fibrin sealants, drain clamping and compression bandaging, have been reported to be successful in some studies, ${ }^{16-18}$ although not as part of large, prospective, randomised controlled trials.

Although evidence supports the notion of a reduced allogenic blood requirement with the retransfusion of collected blood, ${ }^{5-13}$ some studies have called this into question. ${ }^{15,19-21}$ Table I outlines some prospective, randomised controlled trials in the literature that have studied autologous drains and compared them with standard vacuum drainage in total knee replacement (TKR).
}

In order to clarify this debate further, we report the outcome of a prospective, randomised controlled trial comparing the use of allogenic blood and the incidence of perioperative complications after uncomplicated TKR when using either standard vacuum drainage (blood discarded) or autologous retransfusion drains.

\section{Patients and Methods}

We undertook this trial with the approval of our local ethics committee. The study was conducted in a large district general hospital.

Between May 2005 and December 2005, 178 patients were entered into the study. In a pre-assessment clinic patients were randomly assigned into two groups (standard drain or autologous retransfusion) by sealed envelope after a full discussion about the trial and after providing specifically-designed information leaflets. All patients aged over 55 years with osteoarthritis and/or inflammatory arthritis of the knee, and awaiting TKR, were considered for the study. Patients with bleeding disorders and Jehovah's Witnesses were excluded. Intraoperatively, patients requiring a more complex procedure, such as the insertion of stemmed implants and augments, were excluded. Patient demographics, including gender, age and pre-operative diagnosis, are shown in Table II. There were 86 patients in the control 
Table I. Published prospective randomised controlled trials assessing the efficacy of autologous retransfusion drains compared with standard vacuum drainage in patients undergoing unilateral total knee replacement

\begin{tabular}{|c|c|c|c|c|c|c|}
\hline \multirow[b]{2}{*}{ Authors } & \multicolumn{2}{|c|}{ Number of patients } & \multirow[b]{2}{*}{ Autologous drain } & \multicolumn{2}{|c|}{ Patients needing allogenic blood (\%) } & \multirow{2}{*}{$\begin{array}{l}\text { Reduction of } \\
\text { allogenic blood usage (\%) }\end{array}$} \\
\hline & Control group & Study group & & Control group & Study group & \\
\hline Majkowski et al $^{5}$ & 20 & 20 & Solcotrans & 95 & 35 & 64 \\
\hline Heddle et $\mathrm{al}^{8}$ & 40 & 39 & Solcotrans & 67.5 & 25.7 & 62 \\
\hline Newman et $\mathrm{al}^{7}$ & 35 & 35 & Dideco 797 & 80 & 9 & 86 \\
\hline Steinberg et al ${ }^{6}$ & 171 & 194 & SureTrans & 52 & 18.6 & 65 \\
\hline Cheng et $\mathrm{al}^{25}$ & 34 & 26 & DONOR & 62 & 18 & 44 \\
\hline Abuzakuk et $\mathrm{al}^{21}$ & 52 & 52 & Bellovac & 23 & 25 & 0 \\
\hline This study & 86 & 92 & Bellovac & 15.1 & 13 & 2 \\
\hline
\end{tabular}

Table II. Patient demographics

\begin{tabular}{lll}
\hline & Control group & Study group \\
\hline Mean age in yrs (range) & 70.4 (57.9 to 87.1) & 70.3 (55.2 to 88.5) \\
Gender (men:women) & $39: 47$ & $43: 49$ \\
Pre-operative diagnosis (OA:RA) & $3: 83$ & $5: 87$ \\
\hline
\end{tabular}

* OA, osteoarthritis; RA, rheumatoid arthritis

group (standard vacuum drain) and 92 in thestudy group (autologous retransfusion drain).

Surgical technique and post-operative management. All patients received a cemented total condylar knee replacement. The implants used were the press-fit condylar (PFC) (Depuy, Leeds, United Kingdom), Freeman-Samuelson (Finsbury Orthopaedics, Leatherhead, United Kingdom) or Natural Knee II (NKII; Zimmer Ltd, Swindon, United Kingdom). The surgical technique, particularly the retention or substitution of the posterior cruciate ligament (PCL), varied between four teams, as did the techniques of anaesthesia, but the principles were similar. The PCL was preserved in 15 patients $(17.4 \%)$ in the control group and $18(19.6 \%)$ in the study group. Before inflation of a pneumatic tourniquet, all patients received one $1.5 \mathrm{~g}$ dose of intravenous cefuroxime and two further $750 \mathrm{mg}$ post-operative doses at eight-hourly intervals. The tourniquet was released before closure and one deep drain was inserted within the joint space. The drain was connected either to a standard vacuum chamber or to the Bellovac ABT autotransfusion system (Astra Tech, Mölndal, Sweden). The negative pressure in the standard vacuum drains was $100 \mathrm{mgHg}$ and in the Bellovac system $90 \mathrm{mmHg}$. The Bellovac consisted of a blood collection suction bellows connected to an autologous transfusion bag with a $200 \mathrm{~mm}$ filter, and a oneway valve. The transfusion bag was connected to a transfusion set with a $40 \mathrm{~mm}$ filter. The drain was opened 20 minutes after tourniquet release. The shed blood was returned to the patient after collecting up to $500 \mathrm{ml}$ and no later than six hours after surgery. A maximum of $1200 \mathrm{ml}$ was retransfused. Blood collected into the vacuum drains of the control group was discarded.

Thromboprophylaxis was continued until the patient was discharged and comprised one daily 2.5 IU dose of fragmin (a low-molecular-weight heparin (LMWH)) and anti-embolism stockings. During the post-operative period individual teams made their own decisions about the use of antibiotics for potential wound infections or the discontinuation of LMWH for persistent wound drainage.

Transfusion criteria. We standardised the transfusion criteria in order to allow an accurate comparison between the two groups. Allogenic blood was transfused if the haemoglobin level fell below $8 \mathrm{~g} / \mathrm{dl}$, or if the patient developed clinical signs of anaemia, such as tachycardia and postural hypotension, in the presence of a haemoglobin level of $8 \mathrm{~g} / \mathrm{dl}$ to $10 \mathrm{~g} / \mathrm{dl}$. All drains were removed 24 hours after surgery and the volume of blood collected was recorded. Haemoglobin measurements were taken at 24, 48 and 72 hours, and the overall length of stay in hospital was noted. The use of allogenic blood transfusions and post-operative complications, including wound infection, thromboembolic events and returns to the operating theatre, were also recorded.

Statistical methods. The sample size was calculated based on a reduction in transfusion requirement of $50 \%$ between the two groups, with a power of $90 \%$ at the $5 \%$ significance level. Statistical analysis was performed using a one-way analysis of variance (ANOVA) for the assessment of change in haemoglobin levels over time. Student's $t$-test was used to analyse differences in drainage between the two groups. Chi-squared analysis was used to assess the allogenic blood transfusion requirements and the length of stay between the groups. All analyses were undertaken using SPSS version 
Table III. Pre- and post-operative haemoglobin levels and use of allogenic blood for control and study groups

\begin{tabular}{|c|c|c|c|}
\hline & Control group & Study group & p-value \\
\hline Mean (SD) pre-operative haemoglobin (g/dl) & $13.4(1.33)$ & $13.2(1.22)$ & $0.864^{*}$ \\
\hline \multicolumn{4}{|l|}{ Mean (SD) post-operative haemoglobin (g/dl) } \\
\hline 24 hours & $10.4(1.59)$ & $10.5(1.49)$ & $0.998^{\dagger}$ \\
\hline 48 hours & $10.2(1.49)$ & $10.5(1.48)$ & $0.951^{\dagger}$ \\
\hline 72 hours & $10.8(1.58)$ & $11.0(1.40)$ & $0.968^{\dagger}$ \\
\hline Mean (SD) change in haemoglobin (g/dl) & $2.6(0.8)$ & $2.2(0.7)$ & $0.354^{\dagger}$ \\
\hline $\begin{array}{l}\text { Use of allogenic blood (number of patients/total units of blood trans- } \\
\text { fused) }\end{array}$ & $13 / 26$ & $12 / 22$ & $0.439^{*}$ \\
\hline
\end{tabular}

\begin{tabular}{|c|c|c|c|}
\hline & Control group & Study group & p-value (chi-squared test) \\
\hline Mean length of stay in days & 7.0 (3 to 16$)$ & 6.6 (3 to 14$)$ & 0.54 \\
\hline \multicolumn{4}{|l|}{ Complications } \\
\hline Wound infection & 2 & 3 & - \\
\hline Deep-vein thrombosis & 2 & 1 & - \\
\hline Persistent wound drainage (no infection) & 1 & 2 & - \\
\hline Other infections ${ }^{*}$ & 2 & 2 & - \\
\hline Returns to operating theatre & 0 & 1 & - \\
\hline
\end{tabular}

* urinary tract and chest

11.0 for Windows (SPSS Inc., Chicago, Illinois). A p-value $<0.05$ was considered statistically significant.

\section{Results}

The mean drainage volumes between the two groups were comparable, being $638 \mathrm{ml}$ (86 to 1470) in the control group and $659 \mathrm{ml}(100$ to 1900$)$ in the study group. This difference was not significant (Student's $t$-test, $\mathrm{p}=0.468$ ). Of the 92 patients in the study group, $84(91.3 \%)$ were retransfused with a mean of $481 \mathrm{ml}$ of blood (200 to 1110). There were five patients who were not retransfused because of low drainage volumes $(<100 \mathrm{ml})$ and three patients who were not retransfused because of technical difficulties such as problems with the tubing and filter system. These patients were included in the study based on an 'intention to treat' principle. There were no retransfusion-associated complications.

Table III shows the changes in haemoglobin levels and the use of allogenic blood in both groups. The difference between the mean change in haemoglobin level for the two groups was insignificant (ANOVA, $p=0.354$ ). There were 13 patients $(15.1 \%)$ in the control group who required an allogenic transfusion, compared with $12(13 \%)$ in the study group. This difference was not significant (chi-squared test, $\mathrm{p}=0.439$ ).

The mean overall length of stay was comparable between the two groups (control group 7 days ( 3 to 16), study group 6.6 days ( 3 to 14$)(\mathrm{p}=0.54))$. Peri-operative complications and returns to theatre were also comparable (Table IV). There was one patient in the study group who was returned to the operating theatre for re-suturing of a wound dehiscence.

\section{Discussion}

Significant complications after allogenic blood transfusions have been well reported in the literature. ${ }^{2-4}$ However, the best method of reducing the need for transfusion after TKR remains contentious. This study has re-examined the potential benefits of autologous retransfusion compared with standard vacuum drainage after a unilateral TKR.

Autologous retransfusion has gained popularity among patients exposed to the concept, certainly in this study, and by the orthopaedic community as a whole. ${ }^{5-13}$ A recent study recommended its use when combined with tranexamic acid in revision hip surgery. ${ }^{22}$ Initial concerns about the safety of unwashed filtered blood ${ }^{23}$ have been tempered by more recent studies ${ }^{5,7,13}$ suggesting that autologous retransfusion remains safe provided certain protocols are followed. These include abiding to maximum transfusion volumes and retransfusing the blood within six hours of surgery, thereby minimising any haematological or immune reactions. ${ }^{24}$ There were no retransfusion-associated complications in our study using this protocol.

Newman et $\mathrm{al}^{7}$ in a prospective randomised trial, reported a reduced frequency of febrile episodes with retransfusion compared with allogenic transfusion after standard vacuum drainage. Despite this finding, only 70 patients were studied and a large percentage $(80 \%)$ of the control group required allogenic blood. Additionally, the long-term sequelae of these febrile episodes were not 
reported. We found no difference in the incidence of perioperative complications and returns to theatre between our two groups. This direct analysis has rarely been documented in similar studies. $5,7,8,21$

Traditionally, blood collected in a vacuum drain is discarded and decisions about transfusion are individualised, taking into account local protocols and patient comorbidities. There is therefore a widespread discrepancy in the literature with respect to transfusion triggers and the use of allogenic blood. The rate of allogenic transfusion in this study was low and comparable between the groups (15.1\% control group, $13 \%$ retransfusion group). This is in contrast to the published literature (Table I). ${ }^{5-8,21,25}$ The studies, which support the use of autologous drains, each report more than $50 \%$ allogenic blood requirement in their control groups. Majkowski et $\mathrm{al}^{5}$ reported a $95 \%$ allogenic blood requirement in their control group, although their randomised study only included 40 patients. We can only speculate, but our reduced transfusion rate with standard suction drainage $(15.1 \%)$ may relate partly to the transfusion criteria we used. We have shown that with more structured transfusion protocols, patients can be safely shielded from allogenic blood without the need for additional blood conservation strategies.

The need for a drain in TKR has been repeatedly questioned. ${ }^{1,20}$ Although debate continues, the potential benefits of an autologous drainage unit can only be assessed within the remit of a randomised study which includes a treatment arm that uses no drain. Adalberth et $\mathrm{al}^{20}$ prospectively randomised 90 patients into three such groups (no drain, standard vacuum drain, autologous reinfusion drain). They found no difference in the need for allogenic blood transfusion between the groups. A larger study of this nature is clearly required to clarify this further.

Our study therefore confirms the safety, but casts doubt over the efficacy, of retransfusion drains in reducing the need for allogenic transfusion compared with standard suction drainage after TKR.

We would like to thank T. Leppard and D. Capp for their invaluable assistance in study design and data collection.

No benefits in any form have been received or will be received from a commercial party related directly or indirectly to the subject of this article.

\section{Supplementary Material}

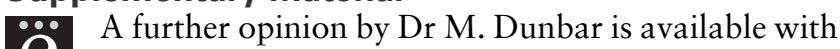
the electronic version of this article on our website at www.jbjs.org.uk

\section{References}

1. Parker MJ, Roberts CP, Hay D. Closed suction drainage for hip and knee arthroplasty: a meta-analysis. J Bone Joint Surg [Am]2004;86-A:1146-52.

2. Schreiber GB, Busch MP, Kleinman SH, Korelitz JJ. The risk of transfusiontransmitted viral infections: the Retrovirus Epidemiology donor study. N Engl J Med 1996;334:1685-90.

3. Gascón P, Zoumbos NC, Young NS. Immunologic abnormalities in patients receiving multiple blood transfusions. Ann Intern Med 1984;100:173-7.

4. Heddle NM, Klama LN, Griffith L, et al. A prospective study to identify the risk factors associated with acute reactions to platelet and red cell transfusions. Transfusion 1993;33:794-7.

5. Majkowski RS, Currie IC, Newman JH. Postoperative collection and reinfusion of autologous blood in total knee arthroplasty. Ann R Coll Surg Eng/1991;73:381-4.

6. Steinberg EL, Ben-Galim P, Yaniv Y, Dekel S, Menahem A. Comparative analysis of the benefits of autotransfusion of blood by a shed blood collector after total knee replacement. Arch Orthop Trauma Surg 2004;124:114-18.

7. Newman JH, Bowers M, Murphy J. The clinical advantages of autologous transfusion. J Bone Joint Surg [Br] 1997;79-B:630-2.

8. Heddle NM, Brox WT, Klama LN, Dickson LL, Levine MN. A randomized trial on the efficacy of an autologous blood drainage and transfusion device in patients undergoing elective knee arthroplasty. Transfusion 1992;32:742-6.

9. Henderson MS, Newman JH, Hand GC. Blood loss following knee replacement surgery, use it don't lose it. Knee 1999;6:125-9.

10. Gannon DM, Lombardi AV Jr, Mallroy TH, et al. An evaluation of the efficacy of postoperative blood salvage after total joint arthroplasty: a prospective randomised trial. $J$ Arthroplasty 1991;6:109-14

11. Rizzi L, Bertacchi P, Ghezzi LM, Bellavita P, Scudeller G. Postoperative blood salvage in hip and knee arthroplasty: a prospective study on cost effectiveness in 161 patients. Acta Orthop Scand 1998;69:31-4.

12. Han CD, Shin DE. Postoperative blood salvage and reinfusion after total joint arthroplasty. J Arthroplasty 1997;12:511-16.

13. Tsumara N, Yoshiya S, Chin T, et al. A prospective comparison of clamping the drain or post-operative salvage of blood in reducing blood loss after total knee arthroplasty. J Bone Joint Surg [Br] 2006;88-B:49-53.

14. Cushner FD, Hawes T, Kessler D, Hill K, Scuderi G. Orthopaedic-induced anemia: the fallacy of autologous donation programs. Clin Orthop 2005;431:145-9.

15. Slagis SV, Benjamin JB, Volz RG, Giordano GF. Postoperative blood salvage in total hip and knee arthroplasty: a randomised controlled trial. J Bone Joint Surg [Br] 1991;73B:591-4.

16. Everts PA, Devilee RJ, Brown Mahoney C, et al. Platelet gel and fibrin sealant reduce allogeneic blood transfusions in total knee arthroplasty. Acta Anaesthesiol Scand 2006;50:593-9.

17. Levy AS, Marmar $\mathbf{E}$. The role of cold compression dressings in the postoperative treatment of total knee arthroplasty. Clin Orthop 1993;297:174-8.

18. Kiely N, Hockings $\mathbf{M}$, Gambhir A. Does temporary clamping of drains following knee arthroplasty reduce blood loss?: a randomised controlled trial. Knee 2001;8:325-7.

19. Marks RM, Vaccaro AR, Balderston RA, et al. Postoperative blood salvage in total knee arthroplasty using the Solcotrans autotransfusion system. J Arthroplasty 1995;10:433-7.

20. Adalberth G, Byström S, Kolstad K, Mallmin H, Milbrink J. Postoperative drainage of knee arthroplasty is not necessary: a randomised study of 90 patients. Acta Orthop Scand 1998;69:475-8.

21. Abuzakuk T, Senthil Kumar V, Shenava Y, et al. Autotransfusion drains in total knee replacement: are they alternatives to homologous transfusion? Int Orthop 2007;31:235-9.

22. Phillips SJ, Chavan R, Porter ML, et al. Does salvage and tranexamic acid reduce the need for blood transfusion in revision hip surgery? J Bone Joint Surg [Br] 2006;88-B:1141-2

23. Southern EP, Huo MP, Mehta JR, Keggi KJ. Unwashed wound drainage blood: what are we giving our patients? Clin Orthop 1995;320:235-46.

24. Sinardi D, Marino A, Chillemi S, et al. Composition of the blood sampled from surgical drainage after joint arthroplasty: quality of return. Transfusion 2005;45:202-7.

25. Cheng SC, Hung TS, TSE PY. Investigation of the use of drained blood reinfusion after total knee arthroplasty: a prospective randomised controlled study. J Orthop Surg (Hong Kong) 2005:13:120-4 